Jurnal Inkofar * Volume 1 No. 1, Juli 2018 * ISSN: 2615-3645 (Print) / 2581-2920 (Online)

Tersedia secara online di: http://www.politeknikmeta.ac.id/meta/ojs/

\title{
TANGGUNG JAWAB INDUSTRI FARMASI TERHADAP PENERAPAN ATURAN PEMERINTAH TENTANG CPOB
}

\author{
Tisa Amalia \\ Program Studi Farmasi, Politeknik META Industri Cikarang \\ Cikarang TechnoPark Building Jalan Inti 1 Blok C1 No 7 Lippo Cikarang Bekasi \\ Email : tisa@politeknikmeta.ac.id
}

\begin{abstract}
Once the importance of drugs in human life so that in the manufacture of drugs must meet the criteria of efficacy, safety, and quality. These criteria must be met from the manufacture, distribution and delivery of drugs into the hands of consumers must be considered for the quality of the drug is maintained until at last the drug is consumed by the patient. At the drugmaking stage, the government has prepared a guideline of Good Manufacturing Practice (CPOB) so that the drugs can meet all three criteria of the above mentioned drugs. The application of CPOB in the pharmaceutical industry aims to ensure the quality of the drugs produced in accordance with the terms and purposes of its use. Aspects regulated in the CPOB include Quality Management, Personnel, Building And Facilities, Equipment, Sanitation And Hygiene, Production, Quality Control, Self Inspection, Quality Audit And Audit \& Supplier Approval, Complaint Handling Products And Product Withdrawal, Documentation, Manufacture And Contract Based Analysis, Qualification And Validation. One of the pharmaceutical industry in Cikarang area of Bekasi Regency is PT. Pharma Laboratories, always make efforts to improve public health by producing safe, effective and quality drugs at affordable prices and apply CPOB in all production process. PT. Pharma Laboratories also has a certificate of CPOB

Keywords: Responsibility of Pharmaceutical Industry, Raising of Regulation of Government, CPOB
\end{abstract}

\begin{abstract}
ABSTRAK
Begitu pentingnya obat dalam hidup manusia sehingga dalam pembuatannya pun obat harus memenuhi kriteria efficacy, safety, dan quality. Kriteria tersebut harus terpenuhi mulai dari pembuatan, pendistribusian hingga penyerahan obat ke tangan konsumen harus diperhatikan agar kualitas obat tersebut tetap terjaga sampai pada akhirnya obat tersebut dikonsumsi oleh pasien. Pada tahap pembuatan obat, pemerintah sudah membuat suatu pedoman (guideline) yaitu Cara Pembuatan Obat yang Baik (CPOB) agar obat dapat memenuhi ketiga kriteria obat yang sudah disebutkan diatas. Penerapan $\mathrm{CPOB}$ dalam industri farmasi bertujuan untuk memastikan mutu obat yang dihasilkan sesuai dengan persyaratan dan tujuan penggunaannya. Aspek yang diatur dalam CPOB meliputi Manajemen Mutu, Personalia, Bangunan Dan Fasilitas, Peralatan, Sanitasi Dan Higiene, Produksi, Pengawasan Mutu, Inspeksi Diri,Audit Mutu Dan Audit \& Persetujuan Pemasok, Penanganan Keluhan Terhadap Produk Dan Penarikan Kembali Produk, Dokumentasi, Pembuatan Dan Analisis Berdasarkan Kontrak, Kualifikasi Dan Validasi. Salah satu industri farmasi yang ada di wilayah Cikarang Kabupaten Bekasi adalah PT. Pharma Laboratories, senantiasa melakukan upaya peningkatan kesehatan masyarakat dengan memproduksi obat yang aman, efektif dan bermutu dengan harga terjangkau dan menerapkan $\mathrm{CPOB}$ dalam seluruh proses produksinya. PT. Pharma Laboratories juga telah memiliki sertifikat CPOB.

Kata Kunci : Tanggung Jawab Industri Farmasi,Penarapan Aturan Pemerinah,CPOB
\end{abstract}




\section{PENDAHULUAN}

Pembangunan bidang kesehatan pada dasarnya ditujukan untuk meningkatkan kesadaran,kemauan dan kemampuan hidup sehat bagi setiap orang untuk mewujudkan derajat kesehatan yang optimal sebagai salah satu unsur kesejahteraan sebagaimana diamanatkan oleh Pembukaan Undang-Undang Dasar Negara Republik Indonesia Tahun 1945 (Peraturan Pemerintah RI Nomor 51 Tahun 2009). Setiap kegiatan dan upaya untuk meningkatkan derajat kesehatan masyarakat yang setinggi-tingginya dilaksanakan berdasarkan prinsip nondiskriminatif,partisipatif,perlindungan, dan berkelanjutan yang sangat penting artinya bagi pembentukan sumber daya manusia Indonesia, peningkatan ketahanan dan daya saing bangsa serta pembangunan nasional ( Undang-Undang RI Nomor 36 Tahun 2009). Tingkat kesadaran masyarakat dalam menggunakan obat yang meningkat dan didukung dengan manguatnya daya beli masyarakat menyebabkan dampak positif pada pertumbuhan industri farmasi di Indonesia. Oleh karena itu, pemerintah harus dapat memastikan bahwa industri farmasi membuat obat yang memenuhi standar mutu yang ditetapkan.

Memperhatikan latar belakang masalah tersebut di atas, maka dalam pembahasan mengenai materi dan substansi penelitian ini penulis memusatkan dan membatasi pembahasannya pada hal-hal sebagai berikut :

1. Bagaimanakah tanggung jawab industri farmasi terhadap penerapan aturan pemerintah tentang CPOB?

2. Sanksi apakah yang diberikan oleh Pemerintah bagi Industri Farmasi yang tidak menerapkan aturan tentang CPOB?

\section{METODE PENELITIAN}

Penelitian Tanggung Jawab Industri Farmasi Terhadap Penerapan Aturan Pemerintah Tentang CPOB menggunakan pendekatan yang bersifat yuridis normatif, yaitu dengan mengkaji atau menganalisa data sekunder yang berupa bahan-bahan hukum terutama bahan hukum primer dan bahan hukum sekunder dengan memahami hukum sebagai seperangkat peraturan atau norma-norma positif di dalam sistem perundang-undangan yang mengatur mengenai kehidupan manusia dan didukung dengan kenyataan di lapangan

\section{HASIL DAN PEMBAHASAN}

\section{A. Tanggung Jawab Industri Farmasi Terhadap Penerapan Aturan Pemerintah} Tentang CPOB

PT. Pharma Laboratories didirikan pada tanggal 19 Desember 2008, atas prakarsa Bapak Dalie Sutanti dan Drs. Asal., Apt.,MM. PT. Pharma Laboratories adalah industri farmasi yang memproduksi obat antibiotic Penicillin dan Sefalosporin.

Pada tahun 2010 PT Pharma Laboratories sudah mempunyai izin usaha industri farmasi yang beralamat di Jalan Cempaka F-18/02, Delta Silicon 2 Lippo Cikarang Bekasi dan hingga sekarang telah menghasilkan kurang lebih 20 produk.

Berdasarkan hasil penelitian penulis bahwa perusahaan PT. Pharma Laboratories sudah mempunyai sertifikat CPOB pertama pada tahun 2011 dan sertifikat CPOB tersebut sudah diperbaharui berlaku sampai tahun 2021. Menurut Peraturan Menteri Kesehatan Republik Indonesia Nomor 1799/MENKES/PER/XII/2010 Tentang Industri Farmasi pada Pasal 8 ayat :

1. Industri farmasi wajib memenuhi persyaratan $\mathrm{CPOB}$

2. Pemenuhan persyaratan $\mathrm{CPOB}$ sebagaimana dimaksud pada ayat ( 1 ) dibuktikan dengan sertifikat CPOB

3. Sertifikat CPOB berlaku selama 5 (lima) tahun sepanjang memenuhi persyaratan 
4. Ketentuan lebih lanjut mengenai persyaratan dan tata cara sertifikasi CPOB diatur oleh Kepala Badan

Aspek aspek yang terdapat di dalam aturan CPOB telah diterapkan dengan baik di PT. Pharma Laboratories.Penilaian Tanggung Jawab Industri Terhadap Penerapan Aturan CPOB dilakukan terhadap 12 aspek yaitu :

1. Manajemen Mutu

Berdasarkan hasil wawancara dengan Manager QA yaitu Bapak Graha bahwa PT. Pharma Laboratories ini sudah memiliki kebijakan mutu.

2. Personalia

Sumber daya manusia sangat penting dalam pembentukan dan penerapan sistem pemastian mutu yang memuaskan dan pembuatan obat yang benar. Oleh sebab itu industri farmasi bertanggung jawab untuk menyediakan personil yang terkualifikasi dalam jumlah yang memadai untuk melaksanakan semua tugas.Tugas spesifik dan kewenangan dari personil pada posisi penanggung jawab sudah dicantumkan dalam uraian tugas tertulis. Tiap personil sudah memahami tanggung jawab masing-masing. Berdasarkan hasil wawancara dengan Manager QA yaitu Bapak Graha bahwa untuk jumlah personil di PT. Pharma Laboratories sudah memenuhi kebutuhan kecuali untuk bagian QC masih dibutuhkan lagi 1 orang. Tidak ada rangkap jabatan dalam mengemban tanggung jawab sebagai seorang Kepala Bagian Produksi, Kepala Bagian Manajemen Mutu dan Kepala Bagian Pengawasan Mutu.

Industri farmasi hendaklah memiliki personil yang terkualifikasi dan berpengalaman praktis dalam jumlah yang memadai. Tiap personil hendaklah tidak dibebani tanggung jawab yang berlebihan untuk menghindarkan risiko terhadap mutu obat.

PT. Pharma Laboratories sudah memiliki personil kunci yang sesuai dengan kompetensinya.Pelatihan untuk meningkatkan kompetensi karyawan sudah dilakukan dengan baik oleh perusahaan baik itu pelatihan yang di selenggarakan oleh perusahaan PT Pharma Laboratories itu sendiri maupun pelatihan yang diselenggarakan oleh pihak eksternal. Jadwal pelatihan sudah dibuat oleh perusahaan selama 1 tahun ke depan. Pelatihan diberikan oleh orang yang terkualifikasi.

3. Bangunan dan Fasilitas

Bangunan dan fasilitas untuk pembuatan obat harus memiliki desain, konstruksi dan letak yang memadai serta disesuaikan dengan kondisinya dan dirawat dengan baik untuk memudahkan pelaksanaan operasi yang benar.

PT. Pharma Laboratories berlokasi di Jalan Cempaka blok F-18/02, DeltaSilicon 2, Lippo Cikarang, Bekasi memiliki :

1) luas tanah : :7.444 $\mathrm{m}^{2}$

2) luas bangunan : $45 \times 51,1 \mathrm{~m}$

1. bangunan Cefalosporin : luas area $=45 \times 25 \mathrm{~m}$

2. bangunan Penicillin: luas area $=45 \times 21,5 \mathrm{~m} \mathrm{~m}$

3. bangunan Utilitas: luas area $=45 \times 5 \mathrm{~m}$

Perawatan rutin 1 tahun sekali sudah dilakukan oleh PT. Pharma Laboratories. Semua area di PT. Pharma Laboratories sudah didesain supaya produk yang dihasilkan terjaga kualitasnya. Sistem tata udara laboratorium dengan ruang produksi terpisah.

5. Peralatan

Peralatan yang ada di PT. Pharma Laboratories sudah memiliki desain dan konstruksi yang tepat. Peralatan pembuatan obat ditempatkan dan sudah dikualifikasi dengan tepat. Apabila terdapat kerusakan pada mesin maka akan dilakukan penggantian dengan menggunakan suku cadang yang sesuai dengan mesin yang mengalami kerusakan. 
5. Sanitasi dan Higiene

Ruang lingkup sanitasi dan hygiene meliputi personil, bangunan, perlatan dan perlengkapan, bahan produksi serta wadahnya, bahan pembersih dan desinfeksi, dan segala sesuatu yang dapat merupakan sumber pencemaran produk. Sisa -sisa produksi tidak menyebabkan pencemaran lingkungan dan untuk yang menangani limbah apabila terdapat pencemaran lingkungan dilakukan oleh pihak PPLI.

Semua personil ketika mau masuk bekerja di PT. Pharma Laboratories salah satu persyataran dokumen yaitu dengan membawa surat keterangan dari dokter sebagai pengganti dari tes kesehatan. Apabila sudah menjadi karyawan maka tetap dilakukan pengontrolan kesehatan terhadap karyawannya 1 tahun sekali dengan membawa surat keterangan sehat dari dokter. Rencana ke depan perusahaan akan memfasilitasi untuk dilakukan tes kesehatan di klinik kesehatan yang sudah bekerja sama dengan perusahaan. Setiap personil mengenakan pakaian pelindung yang bersih dan sesuai dengan tugasnya untuk menjamin perlindungan produk dari pencemaran dan untuk melindungi keselamatan personil.

6. Produksi

Produksi di lakukan dan di awasi oleh personil yang kompeten. Penanganan bahan dan produk jadi seperti penerimaan dan karantina, pengambilan sampel, penyimpanan, penandaan, penimbangan, pengolahan, pengemasan dan distribusi dilakukan sesuai dengan prosedur tertulis dan apabila diperlukan dilakukan pencatatan.

a. Alur Produksi PT. Pharma Laboratories

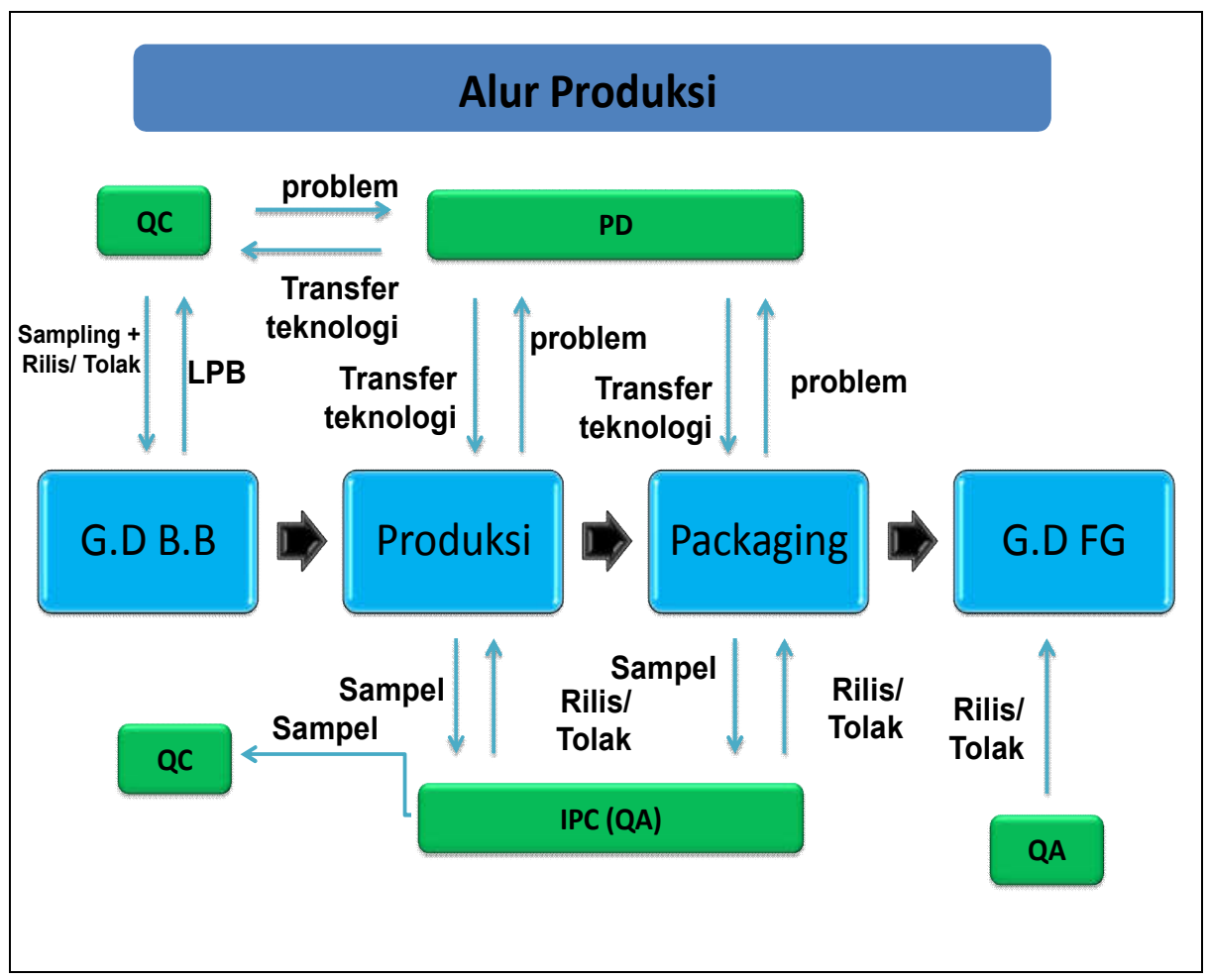

Gambar 1. Alur Produksi PT. Pharma Laboratories 
b. Alur Proses Produksi Tablet PT. Pharma Laboratories

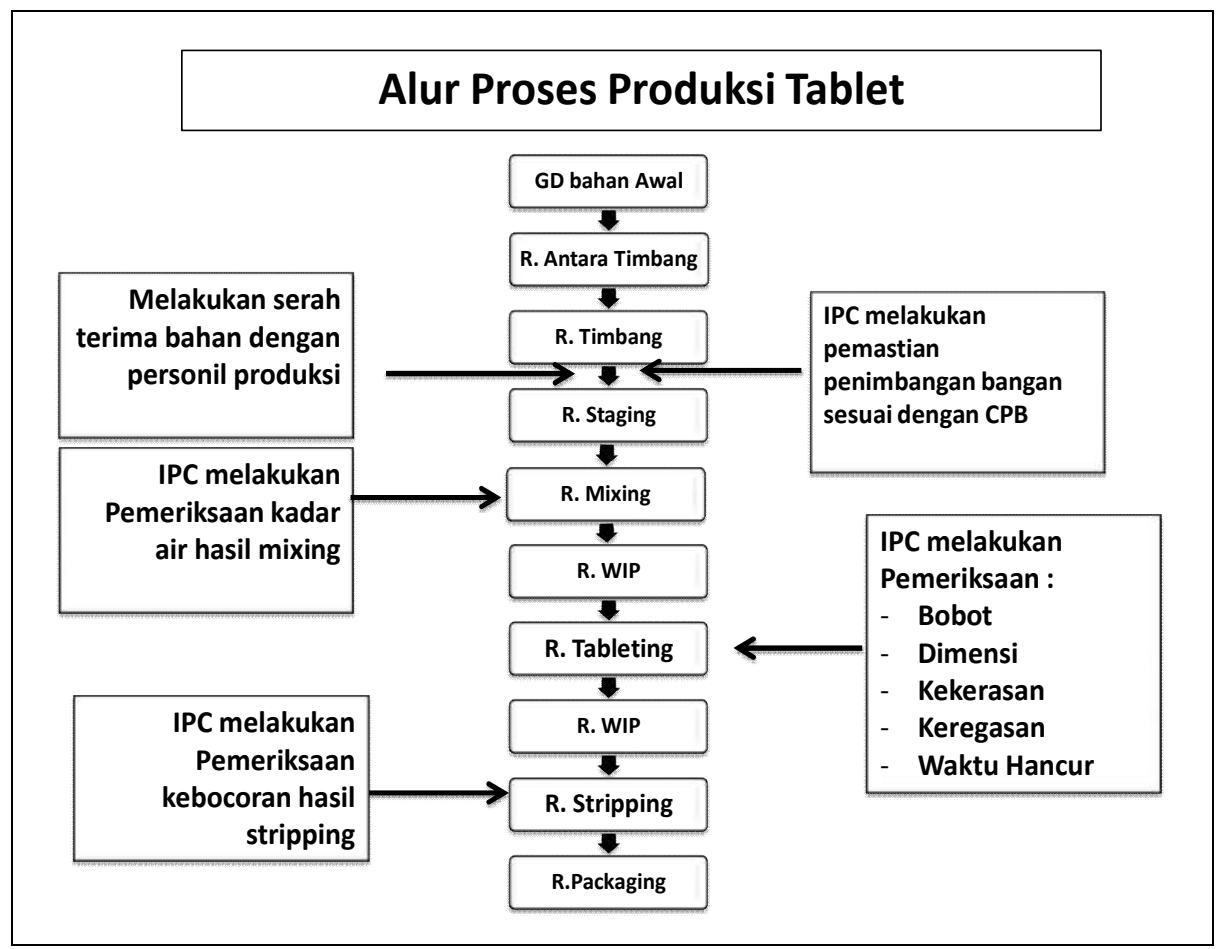

Gambar 2. Alur proses produksi tablet PT. Pharma Laboratories

c. Alur Proses Produksi Kapsul di PT. Pharma Laboratorie

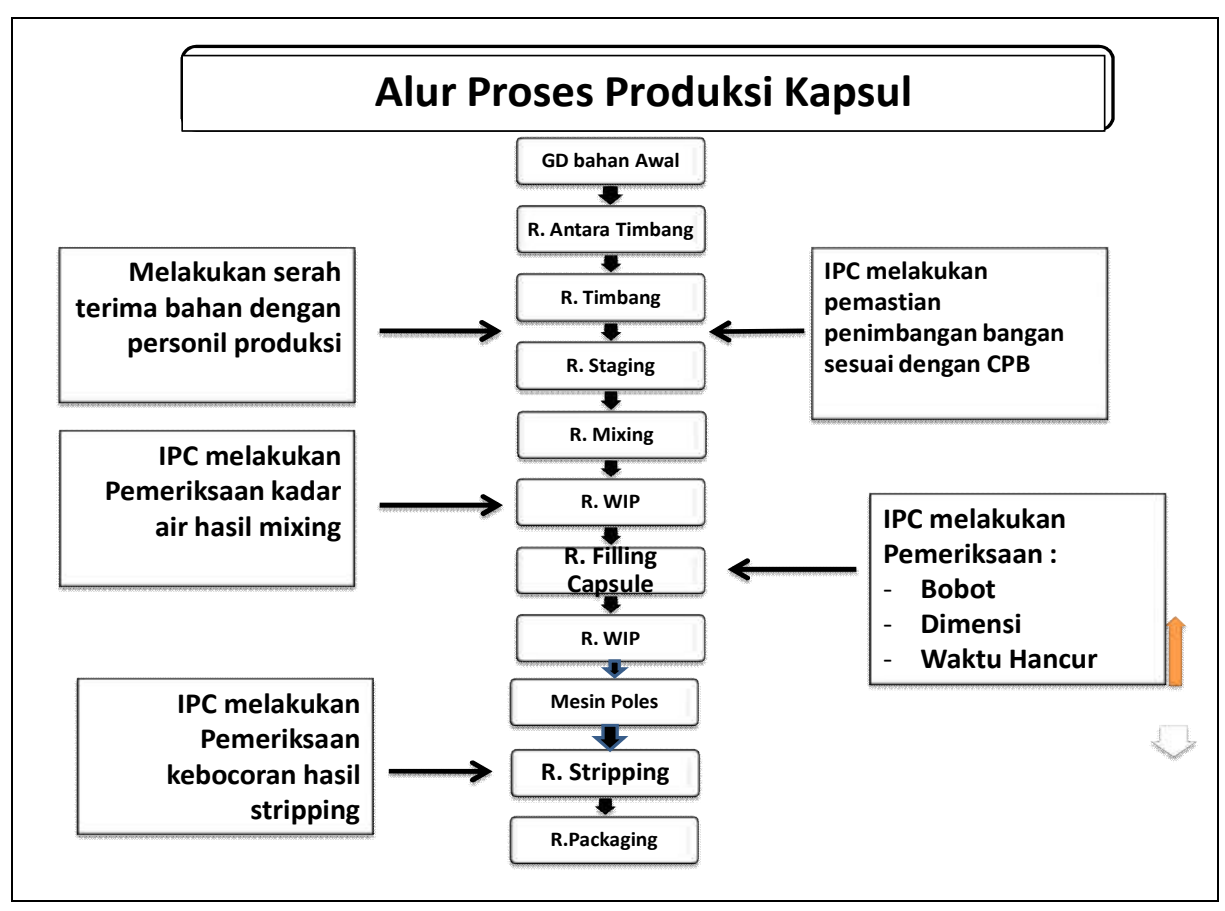

Gambar 3. Alur Proses Produksi Kapsul 
d. Alur Proses Produksi Dry Syrup di PT. Pharma Laboratories

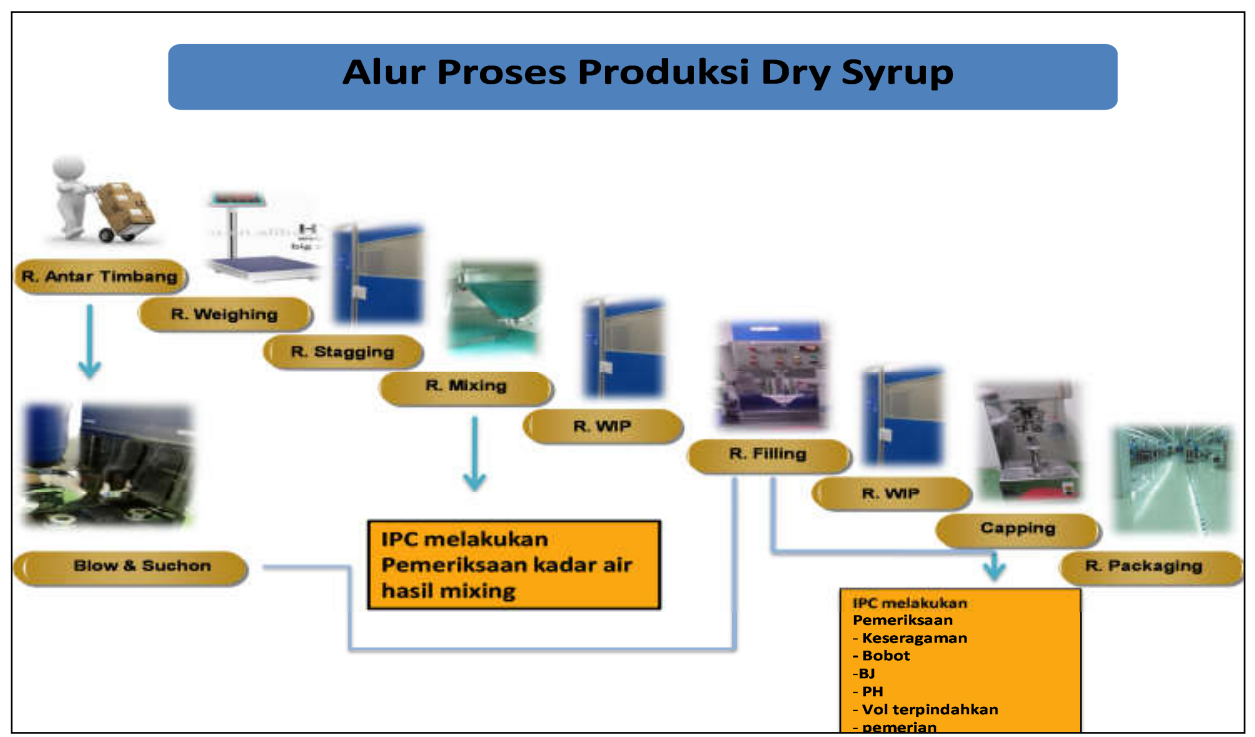

Gambar 4. Alur proses produksi Dry Syrup

7. Pengawasan Mutu

Pengawasan Mutu merupakan bagian yang esensial dari Cara Pembuatan Obat yang Baik untuk memberikan kepastian bahwa produk secara konsisten mempunyai mutu yang sesuai dengan tujuan pemakaiannya. Keterlibatan dan komitmen semua pihak yang berkepentingan pada semua tahap merupakan keharusan untuk mencapai sasaran mutu mulai dari awal pembuatan sampai kepada distribusi produk jadi. Terdapat bukti sertifikat analisa dari pemasok dan terdapat pemantauan dan kualifikasi terhadap lemari asam.

8. Inspeksi Diri, Audit Mutu Dan Audit \& Persetujuan Pemasok

Inspeksi diri di PT. Pharma Laboratories sudah dilakukan oleh petugas yang memiliki kompetensi di bidangnya. Petugas melakukan inspeksi diri mulai dari audit diri maupun audit dokumen.

9. Penanganan Keluhan Terhadap Produk Dan Penarikan Kembali Produk PT. Pharma Laboratories pernah mengalami penarikan kembali produknya. Ketika kejadian tersebut terjadi maka PT. Pharma Laboratories langsung mengambil langkah cepat dengan melakukan pengecekan ulang dengan produk sampel yang masih tertinggal sehingga produk yang ditarik bisa kembali di edarkan dengan tetap mempertahankan kualitas dan mutu. Terdapat SOP apabila terjadi keluhan terhadap produk dan penarikan kembali produk.

10. Dokumentasi

Setiap protap yang ada di PT . Pharma Laboratories selalu disosialisasikan kepada tiap personil yang ada. Protap tersebut selalu di review dan akan mengalami perubahan setiap ada perubahan kebijakan dari Pemerintah atau kebijakan dari perusahaan sendiri. Dokumen yang ada di perusahaan ada sistem kontrolnya sehingga kegiatan dokumentasi menjadi lebih rapih dan jelas.

Dokumentasi yang jelas adalah fundamental untuk memastikan bahwa tiap personil menerima uraian tugas yang relevan secara jelas dan rinci sehingga memperkecil resiko terjadi salah tafsir dan kekeliruan yang biasanya timbul karena hanya mengandalkan komunikasi lisan. 
Jurnal Inkofar * Volume 1 No. 1, Juli 2018 * ISSN: 2615-3645 (Print) / 2581-2920 (Online)

Tersedia secara online di: http://www.politeknikmeta.ac.id/meta/ojs/

11. Pembuatan Dan Analisis Berdasarkan Kontrak

PT. Pharma Laboratories bekerja sama dengan PT. Prisma Pharma Internusa yang merupakan Pedagang Besar Farmasi (PBF). Yang beralamat di Jl. MulyaJayano.16, Cipinang Muara, Jakarta.

PT. Pharma Laboratories berkerja sama dengan PT. Immortal untuk Toll Out Manufacturing untuk produksi obat Non Betalactam dan produk yang di produksi Amlodipine $5 \mathrm{mg}$, Amlodipine $10 \mathrm{mg}$ dan Griseofulvin $500 \mathrm{mg}$.

Perjanjian kerjasama dengan kedua perusahaan tersebut sudah dibuat secara jelas sehingga masing - masing pihak memiliki tanggung jawab dan kewajiban yang jelas. Pembuatan dan analisis berdasarkan kontrak dibuat secara benar, disetujui dan dikendalikan untuk menghindarkan kesalahpahaman yang dapat menyebabkan produk atau pekerjaan dengan mutu yang tidak memuaskan.

Menurut Peraturan Menteri Kesehatan Republik Indonesia Nomor 1799/MENKES/PER/XII/2010 Tentang Industri Farmasi pada pasal Pasal 21 ayat :

3) Industri farmasi dapat membuat obat secara kontrak kepada industri farmasi lain yang menerapkan $\mathrm{CPOB}$

4) Industri farmasi pemberi kontrak wajib memiliki izin industri farmasi dan paling sedikit memiliki 1 fasilitas produksi sediaan yang telah memenuhi persyaratan CPOB

5) Industri farmasi pemberi kontrak dan industry farmasi penerima kontrak bertanggung jawab terhadap keamanan,khasiat/kemanfaatan,dan mutu obat

6) Ketentuan lebih mengenai pembuatan obat kontrak ditetapkan oleh Kepala Badan

12. Kualifikasi dan Validasi

PT. Pharma Laboratories memiliki rencana induk validasi. Sarana penunjang produksi sebelum digunakan dilakukan kualifikasi terlebih dahulu.

CPOB mensyaratkan industri farmasi untuk mengidentifikasi validasi yang perlu dilakukan sebagai bukti pengendalian terhadap aspek kritis dari kegiatan yang dilakukan.

Berdasarkan 12 aspek yang terdapat di dalam Peraturan Kepala Badan Pengawas Obat dan Makanan Republik Indonesia Nomor HK. 03.1.33.12.12.8195 Tahun 2012 Tentang Penerapan Pedoman Cara Pembuatan Obat yang Baik PT. Pharma Laboratories telah melaksanakan tanggung jawab dalam penerapan CPOB sesuai dengan aturan tersebut. Menurut Peraturan Kepala Badan Pengawas Obat Dan Makanan Republik Indonesia Nomor HK. 03.1.33.12.12.8195 Tahun 2012 Tentang Penerapan Pedoman Cara Pembuatan Obat Yang Baik pada Pasal 3 ayat :

1. Industri Farmasi dalam seluruh aspek dan rangkaian kegiatan pembuatan obat dan/atau bahan obat wajib menerapkan pedoman $\mathrm{CPOB}$

2. Pedoman CPOB sebagaimana dimaksud pada ayat (1) tercantum dalam lampiran yang merupakan bagian tidak terpisahkan dari Peraturan ini

B. Sanksi Yang Diberikan oleh Pemerintah bagi Industri Farmasi yang tidak menerapkan aturan tentang CPOB

Sejak berdiri PT. Pharma Laboratories selalu mengikuti aturan CPOB yang telah ditetapkan oleh pemerintah sehingga PT. Pharma Laboratories tidak pernah menerima sanksi dari pemerintah.

Apabila terdapat industri farmasi yang melakukan pelanggaran terhadap aturan CPOB maka ada sanksi yang akan diterima oleh industri tersebut. Menurut Peraturan Menteri Kesehatan Republik Indonesia Nomor 1799/MENKES/PER/XII/2010 Tentang Industri Farmasi pada pasal Pasal 26 ayat : 
Jurnal Inkofar * Volume 1 No. 1, Juli 2018 * ISSN: 2615-3645 (Print) / 2581-2920 (Online)

Tersedia secara online di: http://www.politeknikmeta.ac.id/meta/ojs/

1. Pelanggaran terhadap ketentuan dalam Peraturan ini dapat dikenakan sanksi administratif berupa :

2. Penghentian sementara kegiatan sebagaimana dimaksud pada ayat 1 huruf $d$ dapat dikenakan untuk seluruh kegiatan atau sebagian kegiatan

3. Sanksi administratif sebagaimana dimaksud pada ayat 1 huruf a sampai dengan huruf d diberikan oleh Kepala Badan

4. Sanksi administratif sebagaimana dimaksud pada ayat 1 huruf e dan huruf $\mathrm{f}$ diberikan oleh Direktur Jendral atas rekomendasi Kepala Badan

Menurut Peraturan Kepala Badan Pengawas Obat Dan Makanan Republik Indonesia Nomor HK. 03.1.33.12.12.8195 Tahun 2012 Tentang Penerapan Pedoman Cara Pembuatan Obat Yang Baik pada pasal 6 ayat : 1) Pelanggaran terhadap ketentuan pedoman CPOB dapat dikenai sanksi administratif sebagai berikut
a. Peringatan
b. Peringatan keras
c. Penghentian sementara kegiatan
d. Pembekuan sertifikat $\mathrm{CPOB} / \mathrm{CPBBAOB}$
e. Pencabutan sertifikat $\mathrm{CPOB} / \mathrm{CPBB} A O B$
f. Rekomendasi pencabutan izin industri farmasi

\section{KESIMPULAN}

1. Penerapan $\mathrm{CPOB}$ menjadi tanggung jawab industri farmasi dalam pembuatan obat tertuang dalam Peraturan Kepala Badan Pengawas Obat Dan Makanan Republik Indonesia Nomor HK. 03.1.33.12.12.8195 Tahun 2012 Tentang Penerapan Pedoman Cara Pembuatan Obat Yang Baik dan Peraturan Menteri Kesehatan Republik Indonesia Nomor 1799/MENKES/PER/XII/2010 Tentang Industri Farmasi

2. Apabila terdapat industri farmasi yang melakukan pelanggaran terhadap aturan CPOB maka ada sanksi yang akan diterima oleh industri tersebut. Menurut Peraturan Menteri Kesehatan Republik Indonesia Nomor 1799/MENKES/PER/XII/2010 Tentang Industri Farmasi pada pasal Pasal 26 dan menurut Peraturan Kepala Badan Pengawas Obat Dan Makanan Republik Indonesia Nomor HK. 03.1.33.12.12.8195 Tahun 2012 Tentang Penerapan Pedoman Cara Pembuatan Obat Yang Baik pada pasal 6

\section{DAFTAR PUSTAKA}

\section{Kamus}

Kamus Besar Bahasa Indonesia Edisi Ketiga, Balai Pustaka, Jakarta

Buku

BPOM, 2012. Pedoman Cara Pembuatan Obat Yang Baik Guidelines On Good Manufacturing Practices, Jakarta

Ronny Hanitijo Soemitro, 1990.Metodologi Penelitian Hukum dan Jurimetri, Ghalia Indonesia, Jakarta

Soerjono Soekanto, 1986.Pengantar Penelitian Hukum, UI PRESS, Jakarta

Sugiyono, 2007. Statistika Untuk Penelitian, Alfabeta, Bandung

\section{Peraturan Perundang-Undangan}

Peraturan Kepala Badan Pengawas Obat Dan Makanan Republik Indonesia Nomor HK.04.1.33.12.11.09937 Tahun 2011 Tentang Tata Cara Sertifikasi Cara Pembuatan Obat Yang Baik ( Berita Negara Republik Indonesia Tahun 2012 Nomor 397 ) 
Jurnal Inkofar * Volume 1 No. 1, Juli 2018 * ISSN: 2615-3645 (Print) / 2581-2920 (Online)

Tersedia secara online di: http://www.politeknikmeta.ac.id/meta/ojs/

Peraturan Kepala Badan Pengawas Obat Dan Makanan Republik Indonesia Nomor HK. 03.1.33.12.12.8195 Tahun 2012 Tentang Penerapan Pedoman Cara Pembuatan Obat Yang Baik ( Berita Negara Republik Indonesia Tahun 2013 Nomor 122 )

Peraturan Menteri Kesehatan Republik Indonesia Nomor 1799/MENKES/PER/XII/2010 Tentang Industri Farmasi

Undang-Undang No 36 Tahun 2009 tentang Kesehatan (Lembaran Negara Republik Indonesia Tahun 2009 Nomor 144, Tambahan Lembaran Negara Republik Indonesia Nomor 5063)

Undang-Undang Nomor 51 Tahun 2009 Tentang Pekerjaan Kefarmasian (Lembaran Negara Republik Indonesia Tahun 2009 Nomor 124, Tambahan Lembaran Negara Republik Indonesia Nomor 5044 ) 